\title{
EFFECTS OF AUDIT INTERNAL PERFORMANCE MEASURES, PROFESSIONAL EXPERTISE, AND INTERNAL AUDITOR WORK EXPERIENCE ON UNIVERSITY PERFORMANCE
}

\author{
Roza Mulyadi \\ roza_mulyadi2102@yahoo.com
}

Ahyakudin Ahyakudin

ahyakudin_2000@yahoo.com

Mukhtar

star.muk@gmail.com

Universitas Sultan Ageng Tirtayasa

\begin{abstract}
ABSTRAK
The purpose this research is to research influenc of internal audit performance measures, professional expertise and auditor work experience towards state universities in Banten. The population in this study were auditors of the Internal Audit Unit (SPI) at State Universities in Indonesia. The research sample is the SPI auditor and the former State University SPI auditor in Banten. Data collection is done by coming directly to the SPI auditor and former auditor of State University SPI in Banten. This research was conducted by survey method through a questionnaire to SPI auditors and former SPI auditor of State University in Banten. Total of State Universities in Serang is 4 universities. From the survey result, the number of SPI auditors at State University in Banten is 117, consisting of 73 former SPI auditors and 44 SPI auditors. So that, the number of distributed questionnaires same as proportion of total samples or respondents is 117 questionnaires. Data processing until hypothesis testing in this study uses SPSS. The results of this study are (1) size of internal audit performance has a significant positive effect on university performance, (2) professional expertise has no significant positive effect on university performance and (3) work experience of internal auditors has a significant effect on university performance.
\end{abstract}

\section{Keywords : Internal Audit Performance Measures,}

\section{Pendahuluan}

Penelitian ini mencoba untuk mengusulkan struktur hubungan antara karakteristik audit internal seperti pengaruh ukuran kinerja internal audit, keahlian profesional dan pengalaman kerja auditor internal terhadap kinerja perguruan tinggi negeri di Banten. Kehadiran departemen audit internal sangat penting karena dianggap sebagai unsur utama dalam menggunakan sistem akuntansi pada gilirannya, dan dapat membantu dalam mengevaluasi pekerjaan audit internal di perguruan tinggi negeri.departemen. Audit internal adalah bagian penting dari struktur kelola pemerintahan dalam sebuah organisasi pemerintahan seperti inspektorat meliputi kegiatan pengawasan yang dilakukan oleh dewan direksi dan komite audit untuk memastikan proses pelaporan keuangan yang kredibel (Badan Pengawasan Umum, 1994). Konsisten dengan penelitian sebelumnya tentang pentingnya audit internal, penelitian ini memberikan penjelasan tentang hubungan antara audit internal dan kinerja pemerintahan. Audit internal pemerintah merupakan bagian internal pemerintah yang mengawasi jalannya pemerintahan. Audit internal adalah bagian penting dari struktur 
organisasi pemerintah (Coram, Ferguson, dan Moroney, 2008). Jika menjalankan fungsi audit internal yang dikonfigurasi dengan baik, audit internal dapat memainkan peran penting dalam proses pemerintahan dan akuntabilitas lembaga-lembaga sektor publik melalui penilaian mereka pada efektivitas pengendalian organisasi kunci, tata kelola dan proses manajemen risiko (Asare, 2009). Hal ini didukung D'Silva dan Ridley (2007) bahwa audit internal dan praktiknya dapat menjadikan profesi auditor dalam manajemen risiko, pengendalian dan proses tata kelola pada level strategis dan operasional.

Sarens dan Beelde (2006) menyebutkan empat dimensi dari audit internal yaitu evaluasi, diagnosis, memberi informasi, dan memberi rekomendasi. Dijelaskan lebih lanjut bahwa audit internal berperan mengevaluasi, melaporkan pendapatnya berkaitan dengan kelemahan yang ada pada proses yang berjalan dan pengendalian internal, kemudian memberikan saran yang mungkin dapat meningkatkan kinerja auditan. Inilah sebabnya menurut Sarens dan Beelde (2006) manajemen senior di Belgia mengharapkan audit internal melengkapi perannya untuk mendukung manajemen, meliputi monitoring dan peningkatan manajemen risiko dan pengendalian internal, serta memantau budaya organisasi. Tujuan utama dari penelitian ini adalah untuk mengisi kesenjangan dalam literatur dan memberikan kesempatan untuk penelitian masa depan mendalami untuk menyelidiki hubungan ini. Efisiensi audit internal membantu mengembangkan karya pemerintahan karena laporan keuangan mencerminkan kualitas departemen audit internal. Tiga mekanisme monitoring telah disorot dalam literatur CG, yaitu, audit eksternal, audit internal dan direktur (Al Matarneh, 2011; Anderson et al 1993;. Blue Ribbon Committee, 1999; IIA, 2003). Menurut American Accounting Association, internal audit adalah proses sistematis untuk secara objektif memperoleh dan mengevaluasi asersi mengenai tindakan dan kejadian-kejadian ekonomis untuk meyakinkan derajat kesesuaian antara asersi ini dengan kriteria yang ditetapkan dan mengomunikasikannya ke pengguna yang berkepentingan.

Menurut Robert Tampubolon ( $2005: 1$ ) bahwa : "fungsi audit intern lebih berfungsi sebagai mata dan telingga manajemen, karena manajemen butuh kepastian bahwa semua kebijakan yang telah ditetapkan tidak akan dilaksanakan secara menyimpang". Strategi keuangan dan korporasi dari pemerintahan didukung oleh sistem internal yang efektif di mana audit internal memiliki peran penting dalam meningkatkan keandalan sistem pengendalian internal, meningkatkan proses manajemen risiko dan di atas yang lainya dapat juga memuaskan kebutuhan pengguna internal. Dukungan audit internal meningkatkan sistem tanggung jawab terhadap pemilik dan pemangku kepentingan lainnya (Eighme \& Cashell, 2002). Dengan adanya kerjasama ,departemen audit internal menyediakan para pekerja yang handal, disiplin dan mampu memberikan yang terbaik, objektif memberikan layanan yang netral kepada menejemen, dewan direksi ,dan komite audit. Sedangkan stekcholder tertarik dalam pengembalian investasi,dan laporan yang dapat dihandalkan terhadap kinerja keuangan dan praktek bisnis dari pemerintahan (Ljubisavljević \& Jovanovic, 2011). Keberhasilan reformasi yang dilakukan pemerintah indonesia antara lain diukur dari tata kelola (good governance) dibidang keuangan yang mengarah kepada penerapan prinsip - prinsip transparansi dan akuntabilitas. Akuntabilitas dan transparansi keuangan negara dapat tercapai dengan pengelolaan dan pertanggungjawaban keuangan negara yang dilakukan melalui pengawasan keuangan oleh unit - unit pengawasan auditor internal dan tindakan pengendalian oleh instansi Pentingnya Sistem Pengendalian intern adalah memberikan sinyal yang baik pada masyarakat bahwa pengelolaan keuangan negara telah dilakukan secara efisien dan efektif.

Pemeriksaan intern adalah pemeriksaan yang dilakukan oleh bagian internal audit di pemerintahan, baik terhadap laporan keuangan dan catatan akuntansi di pemerintahan, maupun ketaatan terhadap kebijakan manajemen puncak yang telah ditentukan dan ketaatan terhadap peraturan pemerintah dan ketentuan-ketentuan dari ikatan profesi yang berlaku 
(Sukrisno Agoes, 2004:221). Ukuran keberhasilan auditor internal yaitu efektivitas saran dan rekomendasi dalam penyelesaian permasalahan yang dihadapi auditee dan mampu memberikan nilai tambah untuk keberlangsungan lembaga pemerintahan seperti inspektorat. Konsorsium Organisasi Profesi Audit Internal (2004:4) menyatakan bahwa agar dapat mengemban kepercayaan yang semakin besar dan menjalankan peran tersebut dengan baik, auditor internal memerlukan suatu kode etik dan standar yang seragam dan konsisten, yang menggambarkan praktik-praktik terbaik audit internal, serta merupakan ukuran kualitas pelaksanaan tugas untuk memenuhi tanggung jawab profesinya. Prinsip-prinsip perilaku yang berlaku bagi internal auditor menurut IIA dalam Amin Widjaja Tunggal (2012:200) antara lain integritas, objektivitas, kerahasiaan. Integritas diperlukan agar auditor dapat bertindak jujur dan tegas dalam melaksanakan audit. Objektivitas diperlukan agar auditor internal tidak menerima apapun yang dapat mempengaruhi atau dianggap mempengaruhi pertimbangan profesional (professional judgement) mereka. Kerahasiaan (Confidentiality) diperlukan agar Auditor Internal tidak menggunakan informasi untuk keuntungan pribadi atau dalam setiap keadaan yang dapat melanggar hukum atau mengganggu/merusak tujuan organisasi yang sah dan etis serta Kompetensi auditor didukung oleh pengetahuan, keterampilan dan pengalaman yang diperlukan untuk melaksanakan tugas.

Walaupun standar dan kode etik profesi telah ditetapkan, namun masih sering terjadi kasus yang menyebabkan internal auditor sering dituding kurang berfungsi sebagaimana mestinya atau kurang maksimalnya audit internal. Hal ini dikarenakan sulitnya menjaga integritas, objektivitas, kerahasiaan (confidentiality), dan kompetensi yang melekat pada diri auditor internal. Kualitas audit akan lebih objektif bilamana auditor mampu menjaga kerahasiaan. Alim et al; (2007) menyatakan bahwa berbagai fasilitas yang disediakan objek pemeriksaan selama penugasan dapat mempengaruhi objektivitas auditor, serta bukan tidak mungkin auditor menjadi tidak jujur dalam mengungkapkan fakta yang menunjukan rendahnya integritas auditor. Di samping itu, Sukriah et al (2012) mengungkapkan kompetensi juga memberikan dampak pada setiap keputusan yang diambil dalam pelaksanaan audit sehingga diharapkan setiap keputusan yang diambil merupakan keputusan yang tepat. Namun hal yang terjadi yang menunjukan bahwa kualitas audit internal di inspektorat provinsi banten di nilai masih kurang baik. Kasus yang terjadi saat ini adalah masih adanya auditor Intern Pemerintah yang belum berkualitas, seperti dikutip dari (beritakawanua.com/berita/ekonomi) menjelaskan bahwa auditor intern pemerintah saat ini masih dalam keterbatasan kualitas. Hasil survei 2010-2011, menyatakan bahwa 94\% auditor internal pemerintah berada pada tingkat keahlian pemula (belum berpengalaman) yang masih lemah dalam mendeteksi potensi korupsi anggaran pemerintah. Hal ini dikarenakan sumber daya manusia yang belum terlatih secara langsung/lapangan (pemahaman dalam teori saja), kurangnya pengalaman dalam mengikuti seminar-seminar sehingga menjadikan kualitas kerja sumber daya kurang maksimal (tidak siap kerja/perlu pelatihan real), karena auditor internal sangat vital untuk mendongkrak ketaatan dalam menerapkan prinsip good governance.( beritakawanua.com/berita/ekonomi). Berdasarkan Hasil Pemeriksaan BPK RI atas Laporan Keuangan Pemerintah Daerah Tahun Anggaran 2012 dari sembilan entitas yang ada di Provinsi Banten, empat daerah meraih opini WTP yakni Kabupaten Tangerang, Kota Tangerang, Kabupaten Serang, dan Kota Tangerang Selatan. Dua daerah yakni Kabupaten Tangerang dan Kota Tangerang meraih WTP murni, sedangkan dua daerah lainnya meraih WTP-Dengan Paragraf Penjelas. Sedangkan empat entitas lainnya yakni Kota Cilegon, Kota Serang Kabupaten Lebak, dan Kabupaten Pandeglang meraih opini WDP. Pemerintah Kota Cilegon telah melakukan upaya untuk meningkatkan kualitas laporan keuangannya antara lain dengan peningkatan sumber daya manusia melalui pelatihan serta audit internal yang dilakukan oleh internal audit (Inspektorat) tapi kualitas laporan keuangan daerah Kota Cilegon belum menunjukkan peningkatan. LKPD Kota Cilegon selama lima tahun berturut- 
turut (2008-2012) mendapatkan opini Wajar Dengan Pengecualian. Permasalahan yang menjadi pengecualian dalam opini BPK adalah adanya permasalahan kelemahan pengendalian intern dan ketidakpatuhan terhadap peraturan perundangundangan yang berlaku. Permasalahan tersebut terutama terjadi karena: (1) lemahnya sistem pengendalian intern dan implementasinya; (2) lemahnya pengawasan; (3) kelalaian dan kurang cermatnya para pelaksana dalam melaksanakan tugasnya; dan (4) kurangnya pemahaman dari pelaksanan atas ketentuan yang berlaku. Penelitian ini merupakan pengembangan dari penelitian manajemen dan pengukuran kinerja pemerintah dimana membahas tentang serangkaian proses yang membantu organisasi pemerintah mengoptimalkan kinerja mereka yang menyediakan untuk mengatur proses dan sistem yang mendorong kinerja mereka. Kemudian penelitian tentang the realitionship between audit experince and internal audit effectiveness di sektor organisasi dimana membahas tentang pengalaman yang mempunyai peran penting dalam memastikan dalam pencapaian tujuan, pengalaman audit internal berkontribusi terhadap keefektivitasan auditor internal, pengaruh profesionalisme dan independensi auditor internal terhadap kualitas audit di pemerintahan inspektorat.

\section{Tinjauan Pustaka}

\section{Teori Keagenan (Agency Theory)}

Penggunaan teori keagenan telah dipergunakan secara luas baik di sektor privat maupun sektor publik. Para ekonom menggunakan struktur hubungan prinsipal dan agen untuk menganalisis hubungan antara perusahaan dengan pekerja (Faria and Silva, 2013). Sementara di sektor publik, teori keagenan dipergunakan untuk menganalisis hubungan prinsipal-agen dalam kaitannya dengan penganggaran sektor publik (Latifah, 2010; Abdullah, 2012). Teori keagenan menganalisis susunan kontraktual di antara dua atau lebih individu, kelompok atau organisasi. Salah satu pihak (principal) membuat suatu kontrak, baik secara implisit maupun eksplisit dengan pihak lain (agents) dengan harapan bahwa agen akan bertindak/melakukan pekerjaan seperti yang diinginkan principal (Jensen and Meckling, 1976). Eisenhardt (1989) menggunakan tiga asumsi sifat dasar manusia guna menjelaskan tentang teori keagenan yaitu: (1) Manusia pada umumnya mementingkan diri sendiri (self interest), (2) Manusia memiliki daya pikir terbatas mengenai persepsi masa mendatang (bounded rationality), dan (3) Manusia selalu menghindari resiko (risk averse). Berdasarkan asumsi sifat dasar manusia tersebut,manajer sebagai manusia kemungkinan besar akan bertindak mengutamakan kepentingan pribadinya. Hal ini menimbulkan adanya konflik kepentingan antara principal dan agent. Principal memiliki kepentingan untuk memaksimalkan keuntungan mereka sedangkan agent memiliki kepentingan

untuk memaksimalkan pemenuhan kebutuhan ekonomi dan psikologisnya.

Konflik akan terus meningkat karena principal tidak dapat mengawasiaktivitas agent sehari-hari untuk memastikan bahwa agent telah bekerja sesua idengan keinginan dari principal. Permasalahan dalam hubungan antara prinsipal dan agen bersumber dari adanya perbedaan tujuan dan pilihan risiko yang dihadapi seperti regulasi dan kepemimpinan (Eisenhardt, 1989). Adanya asimetri informasi juga menyebabkan terjadinya persoalan dalam hubungan prinsipal-agen,bilamana agen memiliki informasi lebih tentang kinerja aktual, motivasi dan tujuan yang berpotensi menciptakan moral hazard dan adverse selection (Latifah,2010). Adverse selection terjadi karena adanya perbedaan jumlah informasi yang dimiliki oleh principal dan agent sehingga principal tidak mampu membedakan apakah agen melakukan sesuatu yang baik atau tidak (Faria and Silva, 2013). Dalam konteks ini agen cenderung menyembunyikan informasi untuk memperoleh manfaat yang lebih demi keuntungan pribadi. Teori keagenan telah dipraktekkan pada sektor publik khususnya pemerintah pusat maupun daerah. Organisasi sektor publik bertujuan untuk memberikan pelayanan maksimal kepada masyarakat atas sumber daya yang digunakan untuk memenuhi 
hajat hidup orang banyak. Pemerintah tidak dapat melakukan pengelolaan dan pengalokasian sumber daya secara sendirian, sehingga pemerintah memberikan wewenang kepada pihak lain untuk mengelola sumber daya.

Pembuatan anggaran menjadi mekanisme yang penting untuk alokasi sumber daya karena adanya keterbatasan dana yang dimiliki pemerintah.implikasi teori keagenan muncul dalam proses penyusunan anggaran dilihat dari dua perspektif yaitu hubungan antara rakyat dengan legislatif, dan legislatif dengan eksekutif. Ditinjau dari perspektif hubungan keagenan antara legislatif dengan eksekutif, eksekutif adalah agent dan legislatif adalah principal (Halim dan Abdullah, 2006). Apabila dilihat dari perspektif hubungan keagenan legislatif dengan rakyat, pihak legislatif adalah agent yang membela kepentingan rakyat (principal), akan tetapi tidak ada kejelasan mekanisme dan pengaturan serta pengendalian dalam pendelegasian kewenangan rakyat terhadap legislatif.

Hal inilah yang seringkali menyebabkan adanya distorsi anggaran yang disusun oleh legislatif sehingga anggaran tidak mencerminkan alokasi pemenuhan sumber daya kepada masyarakat, melainkan cenderung mengutamakan self-interest para pihak legislatif tersebut. Jika hal ini terjadi, besar kemungkinan anggaran yang disahkan adalah alat untuk melancarkan aksi pencurian hak rakyat atau seringdikenal dengan istilah korupsi (Mauro, 1998; Keefer and Khemani, 2003).

\section{Pengembangan Hipotesis}

\section{Pengaruh Ukuran Internal Audit terhadap Kinerja Perguruan Tinggi Negeri di Banten}

Ukuran Kinerja ini membahas mengenai sistem ukuran, dimana ada faktor yang merupakan ukuran audit internal, sangat penting untuk meningkatkan kinerja pemerintah. Ukuran audit internal bisa juga diukur dengan jumlah tempat duduk audit internal di komite departemen audit internal. Peran ukuran dalam panitia dijelaskan dalam terang teori yang berbeda. Pertama-tama, (1993) studi Jensen tampaknya konsisten dengan Lipton dan Lorsch (1992) yang menyarankan jumlah yang sesuai dari anggota dewan menjadi tujuh sampai delapan. Juga, Firstenberg dan Malkiel (1994) menyatakan bahwa dengan delapan anggota untuk sedikit mendorong konsentrasi yang lebih besar, partisipasi dan interaksi otentik dan diskusi. Konsisten dengan di atas, Shaver (2005) berpendapat bahwa jumlah yang lebih besar sering ditandai dengan difusi tanggung jawab, yang mengarah pada kemalasan sosial, mendorong kelompok fraksionalisasi dan meminimalkan komitmen kelompok untuk memodifikasi strategi maka dari itu di perlukan karakteristik audit internal yang berkualitas sehingga mendorong suatu kinerja yang efektif.

Dari perspektif teori ketergantungan sumber daya, itu mendalilkan bahwa ukuran audit internal yang lebih besar akan menghasilkan kinerja yang unggul karena semakin banyak nya audit internal yang berkompenten dengan berbagai keterampilan, pengetahuan, dan keahlian yang di miliki dapat memberikan kontribusi untuk menciptakan kemajuan yang berkualitas. Selain itu, juga bisa menawarkan keragaman yang akan membantu untuk mendapatkan sumber daya kritis dan meminimalkan risiko lingkungan (Goodstein, Goodstein, Gautam \& Boeker 1994; Ghazal, 2010; Pearce \& Zahra, 1992; Pfeffer, 1987). Meskipun pentingnya audit internal dalam suatu pemerintahan dikonfirmasi, tidak ada penelitian yang dianggap meneliti hubungan antara audit internal dan kinerja pemerintah. Oleh karena itu, penelitian ini mencoba untuk melakukannya mengharapkan bahwa ukuran audit internal membantu untuk meningkatkan kinerja. Dengan demikian, berikut ini diusulkan untuk empiris investigasi:

Kualifikasi dan karakteristik audit internal dapat meningkatkan kualitas audit internal. Anggota dari audit internal yang memiliki kualifikasi tinggi dapat menangani setiap masalah dalam departemen audit internal. Konsisten dengan teori agensi dan teori ketergantungan sumber daya dan pendukung mereka, orang yang mempunyai keahlian membantu meningkatkan kinerja karena mereka memiliki pemahaman yang jelas tentang bagaimana 
menangani operasi dan mencapai pekerjaan mereka dengan kualitas tinggi. Dengan demikian dapat disimpulkan bahwa ukuran audit internal berpengaruh positif pada kinerja pemerintahan dan dapat di simpulkan ukuran kinerja yang berkualitas dapat memberikan kemajuan dan proses yang diharapkan sehingga dapat menciptakan kepuasan kinerja yang akan terpenuhi,

\section{Pengaruh Keahlian Profesional terhadap Kinerja Perguruan Tinggi}

Untuk memperoleh hasil pemeriksaan yang maksimal, seorang pemeriksa harus memiliki kecakapan profesional atau seringdisebutkan dengan profesionalisme. Profesionalisme adalah tingkah laku,kepakaran atau kualitas dari seseorangyang professional. Seseorang yang memiliki jiwa profesionalisme senantiasa mendorong dirinya untuk mewujudkan kerja yang profesional (Suantara, 2014) Pengelolaan keuangan pemerintah yang baik harus didukung audit yang berkualitas, jika kualitas audit rendah, kemungkinan memberikan kelonggaran terhadap lembaga pemerintah melakukan penyimpangan penggunaan anggaran. Selain itu juga mengakibatkan risiko tuntutan hukum terhadap aparatur pemerintah yang melaksanakanya.

Audit Internal adalah suatu fungsi penilaian yang dikembangkan secara bebas yang dilakukan oleh orang yang profesional yang memiliki pemahaman yang mendalam mengenai sistem dan kegiatan operasional organisasi, menjamin kegiatan operasional organisasi telah berjalan efektif dan efisien serta memastikan bahwa sasaran dan tujuan organisasi telah tercapai. Lemahnya pengendalian internal dalam penyelenggaraan pemerintahan daerah merupakan salah satu penyebab terjadinya ketidakefisienan dan ketidakefektifan penyelenggaraan pemerintahan daerah dan tentunya berdampak pada pemborosan anggaran dan keuangan daerah sehingga di butuhkan keahlian profesional dalam menjalankan suatu proses pengendalian internal. Profesionalisme berarti suatu kemampuan yang dilandasi oleh tingkat pengetahuan yang tinggi dan latihan khusus, daya pemikiran yang kreatif untuk melaksanakan tugas-tugas yang sesuai dengan bidang keahlian dan profesinya (Abdul Halim, 2008:13). Auditor dengan pandangan profesionalisme yang tinggi akan memberikan pengaruh positif bagi kinerjanya, sehingga hasil audit laporan keuangan akan lebih dapat dipercaya oleh para pengambil keputusan baik pihak internal ataupun eksternal . Hal ini mendukung penelitian Bamber (2002), Cohen (2001), Dinata Putri (2013) yang menunjukkan bahwa profesionalisme berpengaruh positif terhadap kinerja pemerintahan, yang dimana semakin tinggi tingkat keprofesionalismean auditor maka kinerja yang dihasilkan akan semakin memuaskan. Berdasarkan uraian di atas,

\section{Pengaruh Pengalaman Audit Internal terhadap Kinerja Perguruan Tinggi}

Pengalaman audit internal dimana ketika seseorang memiliki pengalaman bertahuntahun dapat membuat keputusan yang tepat, cepat dan dapat memutuskan suatu keputusan dalam menghadapi situasi apapun. Variabel ini diukur dan dikumpulkan melalui kuesioner yang dikirim ke pemerintahan. Jika auditor memiliki pengalaman yang banyak maka sikap skeptisisme profesional auditor juga akan tinggi. Sebaliknya, jika auditor kurang berpengalaman maka sikap skeptisisme profesional auditor juga akan menurun. Dimana auditor yang tidak berpengalaman akan melakukan atribusi kesalahan lebih besar dibandingkan auditor yang sudah berpengalaman.

Penelitian ini sejalan dengan Nizarudin (2013), Suraidah (2005), Nasution (2012) yang menunjukkan bahwa pengalaman audit berpengaruh secara positif terhadap skeptisisme profesional auditor internal yang ada di pemerintahan dapat disimpulkan semakin banyak pengalaman auditor maka akan semakin meningkatkan skeptisisme profesional auditor kerena pengalaman memegang peranan penting dalam meningkatkan sebuah kinerja kerena 
pengalaman kerja secara langsung maupun tidak langsung akan menambah keahlian auditor internal dalam menjalankan tugasnya.

Ada beberapa studi yang meneliti hubungan antara pengalaman audit internal dan kinerja pemerintahan di kedua negara maju dan negara berkembang. Ada juga kurangnya Studi antara pasar negara berkembang berkembang. Beberapa penelitian terdahulu membahas di bawah ini dalam terang asosiasi ini. Hutchinson dan Zain (2009) mengeksplorasi hubungan antara intern (pengalaman audit dan kualifikasi akuntansi) audit dan kinerja pemerintahan dengan peluang pertumbuhan dan kemandirian komite audit. Penelitian ini menggunakan analisis regresi berganda untuk menguji hubungan antara audit internal dan kinerja pemerintahan dalam menemukan hubungan yang signifikan antara pengalaman kualitas audit internal dan kinerja pemerintahan.

Seperti disebutkan di atas, ada kurangnya penelitian yang meneliti hubungan antara pengalaman audit internal dan kinerja pemerintahan. Selain itu, Al-Matari dkk. (2012) merekomendasikan pemeriksaan ulang hubungan antara pengalaman audit internal dan kinerja pemerintahan. Oleh karena itu,

\section{METODE PENELITIAN}

Adapun Populasi dalam penelitian ini adalah Auditor SPI Perguruan Tinggi Negeri di Banten. Sampel penelitian yaitu auditor SPI dan mantan auditor SPI Perguruan Tinggi Negeri di Banten. Pengumpulan data dilakukan dengan datang langsung ke auditor SPI dan mantan auditor SPI Perguruan Tinggi Negeri di Banten.

Penelitian ini dilakukan dengan metode survey melalui penyebaran kuesioner kepada auditor SPI dan mantan auditor SPI Perguruan Tinggi Negeri di Banten. Jumlah Perguruan Tinggi Negeri yang terdapat di Serang ada 4 perguruan tinggi

\section{Tabel 1}

Penyebaran Kuesioner pada auditor SPI Perguruan Tinggi Negeri di Banten yang Memenuhi Sampel.

\begin{tabular}{|c|c|c|c|c|}
\hline \multirow[t]{2}{*}{ No. } & \multirow[t]{2}{*}{ Nama Perguruan Tinggi } & \multicolumn{2}{|c|}{$\begin{array}{l}\text { Jumlah Auditor yang dijadikan } \\
\text { sampel penelitian }\end{array}$} & \multirow[t]{2}{*}{$\begin{array}{c}\text { Jumlah Penyebaran } \\
\text { kuesioner }\end{array}$} \\
\hline & & $\begin{array}{l}\text { Mantan } \\
\text { Auditor SPI }\end{array}$ & $\begin{array}{l}\text { Auditor SPI yang } \\
\text { sedang berjalan }\end{array}$ & \\
\hline 1. & $\begin{array}{ll}\text { Universitas } & \text { Sultan } \\
\text { Ageng Tirtayasa } & \end{array}$ & 16 & 11 & 27 \\
\hline 2. & $\begin{array}{l}\text { IAIN Sultan Maulana } \\
\text { Hasanuddin }\end{array}$ & 5 & 10 & 15 \\
\hline 3. & $\begin{array}{l}\text { Universitas Pendidikan } \\
\text { Indonesia }\end{array}$ & 32 & 12 & 44 \\
\hline 4. & Universitas Terbuka & 20 & 11 & 31 \\
\hline & Jumlah & 73 & 44 & 117 \\
\hline
\end{tabular}

Tabel 2

\begin{tabular}{|c|c|c|c|c|c|c|c|c|c|c|}
\hline \multirow[t]{2}{*}{ No. } & \multirow[t]{2}{*}{ Nama Perguruan Tinggi } & \multicolumn{3}{|c|}{$\begin{array}{c}\text { Jumlah } \\
\text { Penyebaran } \\
\text { kuesioner }\end{array}$} & \multicolumn{3}{|c|}{$\begin{array}{l}\text { Jumlah kuesioner } \\
\text { yang tidak } \\
\text { kembali }\end{array}$} & \multicolumn{3}{|c|}{$\begin{array}{l}\text { Jumlah kuesioner } \\
\text { yang kembali }\end{array}$} \\
\hline & & M & ASB & Total & $\mathrm{M}$ & ASB & Total & M & ASB & Total \\
\hline 1. & $\begin{array}{l}\text { Universitas Sultan Ageng } \\
\text { Tirtayasa }\end{array}$ & 16 & 11 & 27 & 5 & - & 5 & 11 & 11 & 22 \\
\hline 2. & IAIN Sultan Maulana Hasanud & 5 & 10 & 15 & 2 & - & 2 & 3 & 10 & 13 \\
\hline 3. & Universitas Pendidikan Indonesia & 32 & 12 & 44 & 15 & - & 15 & 17 & 12 & 29 \\
\hline
\end{tabular}




\begin{tabular}{lccccccccc} 
4. Universitas Terbuka & 20 & 11 & 31 & 8 & - & 8 & 12 & 11 & 23 \\
\hline Jumlah kuesioner & 73 & 44 & 117 & 30 & & 30 & 43 & 44 & 87 \\
\hline
\end{tabular}

\section{Rincian Sampel Yang Dapat Diolah}

\section{Uji Kualitas Data}

Sugiyono (2010) mengungkapkan bahwa kualitas data yang dihasilkan dari penggunaan instrumen penelitian dapat dievaluasi melalui uji validitas dan uji reliabilitas. Keabsahan suatu jawaban dari responden sangat ditentukan oleh alat ukur yang telah ditentukan. Prosedur pengujian kualitas data atas data primer peneliti melakukan uji validitas dan reliabilitas. Penelitian ini telah memenuhi syarat keduanya

\section{Uji Asumsi Klasik}

Uji asumsi klasik adalah persyaratan statistik yang harus dipenuhi pada analisis regresi linear berganda. Uji asumsi klasik terdiri dari: uji normalitas, uji multikolinearitas, uji autokorelasi dan uji heteroskedastisitas menggunakan alat statistik SPSS versi 23. Penelitian ini telah lolos dari semua uji Asumsi Klasik dan memenuhi syarat untuk dilanjutkan ke Regresi

\section{Hasil dan Pembahasan Analisis Statistik Deskriptif}

Statistik deskriptif memberikan gambaran atau deskripsi suatu data dilihat dari nilai rata-rata (mean), standar deviasi, minimum, maksimum dan varian (Ghozali, 2010). Data tentang ukuran kinerja internal audit di peroleh melalui kuisioner yang terdiri dari 5 pertanyaan dengan (5) alternatif jawaban $(1,2,3,4,5)$ dari hasil 45 jawaban responden terhadap item pertanyaan di peroleh skor tertinggi 23 dan terendah 14 dengan rata-rata skor sebesar 19,22 dan standar deviasi 2,194

Tabel 3

Analisis Statistik Deskriptif Descriptive Statistics

\begin{tabular}{cccccc}
\hline & N & Minimum & Maximum & Mean & Std. Deviation \\
\hline KIA & 87 & 14 & 23 & 20,23 & 2,197 \\
KPROF & 87 & 13 & 24 & 21,41 & 2,138 \\
PKAI & 87 & 11 & 21 & 17,87 & 1,947 \\
KPTN & 87 & 18 & 25 & 22,95 & 1,564 \\
\hline
\end{tabular}

Valid N
(listwise)

\section{Sumber: Output SPSS yang diolah (2018).}

Dari tabel di atas menunujukkan bahwa nilai minimum variabel ukuran kinerja internal audit (KIA) nilai minimum 14, nilai maksimum 23, standard deviasi 2.197 dan mean 20.23 maka dapat disimpulkan ukuran kinerja internal audit SPI pada PTN di Banten sudah cukup baik. Untuk variabel Keahlian Profesional (KPROF) menunjukkan nilai minimum 13, nilai maksimum 24, standard deviasi 2.138 dan mean 21.41 maka dapat disimpulkan keahlian professional auditor SPI pada PTN di Banten sudah cukup baik. Untuk variabel Pengalaman kerja auditor internal (PKAI) menunjukkan nilai minimum 11, nilai maksimum 21, standard deviasi 1.947 dan mean 17.87 maka dapat disimpulkan keahliah professional auditor SPI pada PTN di Banten sudah baik. Untuk variabel Kinerja perguruan tinggi negeri (KPTN) 
menunjukkan nilai minimum 18, nilai maksimum 25, standard deviasi 1.564 dan mean 22.95 maka dapat disimpulkan kinerja pada PTN di Banten sudah cukup baik.

\section{Uji Koefisien Determinasi}

Tabel 9

Hasil Uji Koefisien Determinasi $\left(\mathbf{R}^{2}\right)$ Model Summary ${ }^{b}$

\begin{tabular}{llrrr}
\hline Model & $\mathrm{R}$ & R Square & Adjusted R Square & \multicolumn{2}{c}{$\begin{array}{c}\text { Std. Error of the } \\
\text { Estimate }\end{array}$} \\
\hline 1 & $0,519^{\mathrm{a}}$ & 0,270 & 0,216 & 1,280 \\
\hline
\end{tabular}

a. Predictors: (Constant), PKAI, KIA, KPROF

b. Dependent Variable: KPTN

Berdasarkan hasil regresi linier berganda ditunjukkan pada tabel diatas didapatkan hasil Adjusted R square sebesar 0,216. Dengan demikian dapat disimpulkan bahwa variabel independen(Ukuran kinerja internal audit, Keahlian profesional, Pengalaman kerja auditor internal) dapat menjelaskan sebesar 21,6\% kepada variabel dependen yaitu Kinerja Perguruan Tinggi, sedanagkan sisanya 78,4\% dapat dijelaskan oleh faktor lain diluar model yang diteliti

\section{Analisis Regresi Berganda}

\section{Tabel 10}

Pengujian Hipotesis

\begin{tabular}{|c|c|c|c|c|c|c|}
\hline \multicolumn{7}{|c|}{ Coefficients $^{a}$} \\
\hline \multirow[b]{2}{*}{ Model } & & \multicolumn{4}{|c|}{ Standardized } & \\
\hline & & B & Std. Error & Beta & $\mathrm{T}$ & Sig. \\
\hline 1 & (Constant) & 12,866 & 2,988 & & 4,306 & ,000 \\
\hline & $\begin{array}{l}\text { KIA } \\
\text { KPROF } \\
\text { PKAI }\end{array}$ & $\begin{array}{l}\text {,255 } \\
, 009 \\
\text {,232 }\end{array}$ & $\begin{array}{l}, 092 \\
, 102 \\
, 112\end{array}$ & $\begin{array}{l}, 387 \\
, 013 \\
, 294\end{array}$ & $\begin{array}{r}2,786 \\
, 093 \\
2,073\end{array}$ & $\begin{array}{l}, 008 \\
, 926 \\
, 045\end{array}$ \\
\hline
\end{tabular}

a. Dependent Variable: KPTN

\section{Konstanta=12,866 PF $=12,866+0,255 \mathrm{KIA}+0,009(\mathrm{KPROF})+0,232(\mathrm{PKAI})+\varepsilon$}

Koefisien variabel $(\mathrm{KIA})=0,255$,Koefisien positif ,Peningkatan $(\mathrm{KPTN})=0,255$

Koefisien variable $(\mathrm{KPROF})=0,009$, Kofisien positif, Peningkatan $(\mathrm{KPROF})=0,009$

Koefisien variabel $(\mathrm{PKAI})=0,232$, Kofisien Positif, Peningkatan $(\mathrm{KPTN})=0,232$

\section{Goodness of Fit Model (Uji F)}

Pengujian $\mathrm{F}$ untuk membuktikan apakah regresi berganda signifikan atau tidak. Hasil ujinya sebagai berikut:

\section{Tabel 11}

Hasil Uji Goodness of Fit (Uji F)

ANOVA $^{a}$

\begin{tabular}{llrrrrr}
\hline Model & & Sum of & & & & \\
\multicolumn{1}{l}{} & Squares & Df & Mean Square & F & Sig. \\
\hline 1 & Regression & 24,783 & 3 & 8,261 & 5,046 &, $005^{\mathrm{b}}$ \\
& Residual & 67,128 & 41 & 1,637 & &
\end{tabular}




\section{Total}

91,911 44

a. Dependent Variable: KPTN

\section{b. Predictors: (Constant), PKAI, KIA, KPROF}

Dengan tingkat signifikan 5\% dan derajat kebebasan df1 $=3$ dan df2 $=47$ maka tabel didapat $\mathrm{F}(2: 47)=2,81$. Dalam perhitungan diperoleh nilai $\mathrm{F}$ hitung lebih besar dari $\mathrm{F}$ tabel, yaitu 5,046>3,20 sehingga Ho ditolak dan Ha diterima. Sedangkan jika dilihat dari nilai probabilitas hitung adalah 0,005 yaitu $<0.05$ maka keputusannya juga menolak Ho yang berarti hal ini menunjukan bahwa model dalam penelitian ini layak untuk dilanjutkan.

\section{Pembahasan}

Berdasarkan hasil pengujian variabel kinerja internal audit (KIA) memiliki arah positif dengan nilai koefisien 0,255 dengan signifikansi kurang dari $0,05(0,008<0,05)$ dan memiliki t-hitung sebesar 2,786,karna t hitung > dari t tabel untuk df (47) (2,786>2.01410).Hasil pengujian dapat disimpulkan bahwa kinerja internal audit (KIA) berpengaruh positif signifikan terhadap Kinerja Perguruan Tinggi. Kontribusi audit internal menjadi semakin penting seiring dengan makin berkembang dan makin kompleksnya sistem usaha dan pemerintahan (Sawyer's, 2005). Auditor internal dengan kompetensi yang baik sesuai akan dapat memahami apa yang harus dikerjakan dan apa fungsi dirinya dalam pekerjaan tersebut. Pemahaman yang baik akan fungsi dan kompetensi yang memadai dari seorang auditor akan menumbuhkan komitmen tinggi terhadap pekerjaanyat. Seorang auditor dengan kompetensi intelektual yang tinggi, dengan tingkat pendidikan sarjana akuntansi misalnya (kompetensi yang sesuai dengan pekerjaan sebagai auditor), akan memahami dengan baik apa tugas dan fungsi seorang auditor internal. Dengan adanya pemahaman yang baik akan tugas dan fungsi sebagai seorang auditor internal yang bertugas melakukan pengawasan dan pencegahan terhadap penyalahgunaan keuangan maka, akan menumbuhkan idealisme terhadap tugas dan tanggungjawab, yang akhirnya akan bermuara pada munculnya komitmen diri untuk membantu perguruan tinggi mencegah penyelewengan keuangan negara. Sehingga berdasrkan penjelaskan di atas dapat di simpulkan bahwa ukuran kinerja auditor internal yang baik dapat menunjang keberhasilan pada kinerja perguruan tinggi tersebut. Sistem pengendalian auditor internal yang efektif akan berpengaruh terhadap kinerja perguruan tinggi (Tresnawati, 2012). Dimana jika ukuran kinerja auditor internal berkualitas sehingga dapat menciptakan suatu kepuasan dan mempeoleh suatu keberhasilan maka akan meningkatkan kualitas kinerja pada perguruan tinggi tersebut maka dari itu disimpulkan bahwa berpengaruh positif signifikan. Hasil penelitian Supriadi dkk. (2014) mendukung penelitian Tresnawati (2012), mengharuskan adanya komitmen, pengawasan melekat agar pengelolaan keuangan dapat dilakukan secara efektif dan efisien.

Variabel Keahlian Profesional (KPROF) memiliki arah positif dengan nilai koefisien 0,009 dengan signifikansi lebih dari $0,05(0,926<0,05)$ dan memiliki t-hitung sebesar0,093, karna t hitung < dari t tabel untuk df (47) $(0,093<2.01410)$ dapat disimpulkan bahwa Keahlian Profesional (KPROF) berpengaruh positif tidak signifikan terhadap Kinerja Perguruan Tinggi. Demir (2011) menyatakan bahwa profesionalisme merupakan salah satu nilai fundamental yang harus tercermin dalam keputusan administratif dan tindakan. Selain itu, dengan profesionalisme yang tinggi, tingkat kebebasan atau independensi auditor tersebut akan semakin terjamin. Dalam melaksanakan tugasnya, seorang auditor juga dituntut untuk memiliki profesionalisme yang tinggi. Profesionalisme auditor merupakan cerminan seberapa jauh seorang auditor dapat mengaplikasikan etika profesi yang harus dijalankan. Selain itu, juga tercermin pada penerapan berbagai ketrampilan dan skill yang optimal dalam 
menjalankan tugastugasnya. Auditor yang profesional akan mendapatkan kepercayaan publik sehingga keraguan hasil dalam audit dapat diminimalisir. Hasil pengujian hipotesis menunjukkan bahwa keahlian auditor tidak berpengaruh terhadap kinerja auditor SPI pada perguruan tinggi. Hal tersebut disebabkan oleh suatu kemungkinan, yaitu berdasarkan pada diskripsi responden, dapat diketahui bahwa masih ada responden cenderung menjawab pertanyaan keahlian auditor dengan tidak setuju, artinya responden belum memiliki keahlian yang memadai sehingga tidak memiliki pengaruh terhadap kinerjanya, tidak sepenuhnya auditor internal menerapkan prosedur kerja secara maksimal. Faktor-faktor yang menyebabkan ketidakpengaruhan tersebut dapat dilihat dari masih adanya kelemahan dari beberapa auditor internal dalam merespon tingkat risiko sehingga tidak memenuhi standar, masih adanya tingkat keraguan dari auditor internal sehingga menimbulkan sikap ketidaktegasan, keterbatasan pengetahuan. Keahlian dari kinerja seorang auditor dapat dilihat dari beberapa temuan yang dapat di peroleh guna dalam mendekteksi kesalahan yang mungkin terjadi tapi tidak menutup kemungkinan auditor internal yang memiliki keahlian profesional tidak akan melakukan kesalahan-kesalahan. Penelitian ini sejalan dengan penilitan dari Pramudyastuti (2014).

Variabel Pengalaman Kerja Auditor Internal (PKAI) memiliki arah positif dengan nilai koefisien 0,232 dengan signifikansi kurang dari $0,05(0,045<0,05)$ dan memiliki t-hitung sebesar 2,073,karna t hitung > dari t tabel untuk df (47) (2,073>2.01410) dapat disimpulkan bahwa Pengalaman kerja auditor internal (PKAI) berpengaruh positif signifikan terhadap Kinerja Perguruan Tinggi. Pengalaman diukur dari seberapa sering seorang auditor terlibat atau menerima peran dalam pelaksanaan atau penugasan audit. Hernadianto (2002) mengatakan bahwa seseorang auditor menjadi ahli terutama diperoleh melalui pelatihan dan pengalaman. Seorang auditor yang lebih berpengalaman akan memiliki skema yang lebih baik dalam mendefinisikan kekeliruan-kekeliruan daripada auditor yang kurang berpengalaman. Auditor akan mengeluarkan seluruh kemampuan terbaiknnya yang didapatkan dari pengalaman yang telah dimiliki melalui tugas-tugas audit yang telah dilaksanakan untuk mendapatkan hasil kinerja yang baik. Semakin berpengalaman seorang auditor diharapkan bahwa akan semakin tinggi kinerja yang dihasilkan sehingga kualitas audit yang baik dapat tercapai. bahwa pengalaman melakukan audit merupakan faktor yang penting yang harus dimiliki oleh auditor. Hal ini terbukti dengan tingkat kesalahan yang dibuat oleh auditor yang tidak berpengalaman lebih banyak daripada auditor berpengalaman, sehingga berdampak signifikan. Penelitian ini sejalan dengan penelitian yang dilakukan oleh Sukriah dkk (2009) bahwa pengalaman kerja berpengaruh positif terhadap kualitas hasil kinerja auditor internal yang berdampak positif pada perguruan tinggi. Dengan demikian, semakin banyak pengalaman kerja, maka semakin meningkat atau semakin baik kualitas hasil pemeriksaan yang dilakukannya Pengalaman kerja juga sangat mempengaruhi keputusan yang akan diambil. Semakin lama seoranng auditor menekuni profesinya maka akan semakin tepat dalam mendeteksi sebuah kesalahan. Sehingga akan dapat meningkatkan kualitas

\section{SIMPULAN DAN SARAN Simpulan}

Berdasarkan hasil penelitian serta pembahasan bab sebelumnya tentang bukti empiris mengenai pengaruh ukuran kinerja internal audit, keahlian profesional, pengalaman kerja auditor internal terhadap kinerja perguruan tinggi. Dapat ditarik kesimpulan bahwa : Ukuran kinerja internal audit berpengaruh positif signifikan terhadap kinerja perguruan tinggi. Hal ini menunjukkan bahwa semakin baik ukuran kinerja internal audit yang dijalankan maka akan meningkatkan kualitas dapat memberikan kemajuan dan proses yang diharapkan sehingga dapat menciptakan kepuasan kinerja yang akan terpenuhi. Keahlian profesional berpengaruh 
positif tidak signifikan terhadap kinerja perguruan tinggi. Hal ini menunjukkan bahwa keahlian profesional tidak berpengaruh pada kinerja perguruan tinggi. Hal-hal tersebut dapat di sebabkan masih adanya kelemhan dari beberapa auditor internal yang tidak memenuhi standar. Pengalaman kerja auditor internal berpengaruh signifikan terhadap kinerja perguruan tinggi . Hal ini menunjukan bahwa semakin lama masa kerja dan pengalaman yang dimiliki auditor internal maka secara langsung maupun tidak langsung akan menambah keahlian auditor internal dalam menjalankan tugasnya dan pengalaman kerja memegang peranan penting dalam meningkatkan suatu kinerja agar dapat menciptakan kualitas yang diingikan secara maksimal.

\section{Keterbatasan Penelitian}

Penelitian ini masih dapat dikembangkan dengan memperhatikan keterbatasan penelitian berikut yang dapat dijadikan referensi penelitian selanjutnya. Keterbatasan penelitian tersebut adalah sebagai berikut: Jumlah responden auditor SPI pada Perguruan Tinggi Negeri terdiri dari mantan auditor dan auditor SPI yang sedang berjalan. Karena apabila respondennya hanya auditor SPI yang sedang berjalan saja maka kekhawatiran jumlah responden dalam peelitian ini tidak cukup bahkan dalam pengolahan data kekhawatiran responden rate dalam penelitian ini kecil.

\section{Saran Penelitian}

Penelitian ini masih dapat dikembangkan dengan memperhatikan saran berikut yang dapat dijadikan referensi penelitian selanjutnya, saran tersebut adalah sebagai berikut : Penelitian selanjutnya sebaiknya menambah unit kerja yang diteliti. Penelitan selajutnya agar di harapkan lebih mampu menganalisis mengenai kinerja audit internal di perguruan tinggi.

\section{DAFTAR PUSTAKA}

Al Matarneh, G.F. (2011). Factors determining the internal audit quality in banks: Empirical Evidence from Jordan. International Research Journal of Finance and Economics, 73, 99-108.

Al-Matari, E.M., Al-Swidi, A.K., Faudziah, H.B., Al-Matari, Y.A. (2012). The Impact of board characteristics on Firm Performance: Evidence from Nonfinancial Listed Companies in Kuwaiti Stock Exchange. International Journal of Accounting and Financial Reporting, 2(2), 310-332.

Al-Shammari, Aid. (2010). The role of the Audit Committees in Corporate Governance in Saudi Arabia.Workshop paper. College of Business Administration - King Saud University.

Anderson, N. J., B. Rippey \& C. E. Gibson (1993). A comparison of sedimentary and diatominferred phosphorus profiles: implications for defining pre-disturbance nutrient conditions. Hydrobiologia 253:357-366.

Blue ribbon committee on improving the effectiveness of corporate audit committees (Blue Ribbon Committee). (1999). Report and Recommendations, Blue Ribbon Committee, New York, NY. charge? Sloan Management Review, 36(1), 27-55.

Clikeman, P.M. (2003). Where auditors fear to tread: internal auditors should be proactive in educating companies on the perils of earnings management and in searching for signs of its use. Internal Auditor, 75-80.

Collier, P., \& A. Gregory (1996). Audit committee effectiveness and the audit fee, The European Accounting Review, 5, 177-198.

D’Aveni, R.A. (1990). Top managerial prestige and organizational bankruptcy, Organization Science, 1(2), 121-42. 
Davidson, R., Goodwin-Stewart, J., Kent, P. (2005,). Internal Governance Structures and Earnings Management. Accounting and Finance, 45, 241-267. Eighme, J., Cashell, J. (2002). Internal auditors' roles in overcoming the financial reporting crisis. International Auditing, 17, 3-10.

Fatimah Mat Yasina and Sherliza Puat Nelsonb(2012). Audit Commite and Internal Audit : Implacations On Audit Quality

Firstenberg, P.B., \& Malkiel, B.G. (1994). The twenty-first century boardroom: Who will be in Ghazali, N. (2010). Ownership structure, corporate governance and corporate performance in Malaysia. International Journal of Commerce and Management, 20(2), 109-119.

Ghozali, Imam. 2011. Aplikasi Analisis Multivariate dengan Program IBM SPSS 19. Semarang: Badan Penerbit Universitas Diponegoro.

Goodstein, J., Gautam, K. \& Boeker, W. (1994) The effects of board size and diversity on strategic change, Strategic Management Journal, 15, 241-250.

Goodwin, J. (2003). The relationship between the audit committee and the internal audit function: Evidence from Australia and New Zealand. International Journal of Auditing 7(3): 263-278.

Goodwin, J., \& P. Kent, 2003, Factors affecting the voluntary use of internal audit, Paper presented at the Annual Meeting of the American Accounting Association, Hawaii.

Goodwin, J., Yeo, T.Y. (2001). Two Factors Affecting Internal Audit Independence and Objectivity: Evidence from Singapore. International Journal of Auditing 5(2), 107-125.

Hala, N. (2003), Sherron Watkins - If capitalists were angels, Internal Auditor 60(11), 38-43.

Hery. 2010. Potret Audit Internal. Bandung: Alfabeta.

Hery. 2013. Auditing (Pemeriksaan Akuntansi I), Cetakan Pertama, Jakarta CAPS (Center Of Academic Publishing Service).

Hillman, A., Dalziel, T. (2003). Boards of directors and firm performance: Integrating agency and resource dependence perspectives. Academy of Management Review, 28(3), 383396.

Hutchinson, M.R., \& Zain, M.M. (2009). Internal audit quality, audit committee independence, growth opportunities and firm performance. Corporate Ownership and Control, 7(2), 50-63.

Institute of Internal Auditors (IIA). (2003). Comment letter to SEC on standards relating to listed company audit committees.

Jensen, M. (1993). The modern industrial revolution, exit and the failure of internal control systems. Journal of Finance, 48, 831-880.

Jupri Lumban Toruan (2015). Pengaruh Indenpendensi, Kompetensi, Pengalaman, dan Pendidikan Terhadap Profesionalisme Auditor.

Lipton, M., Lorsch, J. (1992). Modest proposal for improved corporate governance. Business Lawyer, 12(3), 48-59.

Ljubisavljević, S., Jovanovi, D. ( 2011). Empirical research on the internal audit position of companies in Serbia. Economic Annals, LVI( 191), 123-141.

Mu'azu Saidu BADARA, Siti Zabedah SAIDIN, School of Accountancy, University Utara Malaysia(2013).The Relationship Between Audit Experience and Internal Audit Effectiveness in the Public Sector Organization

New York stock exchange corporate accountability and listing standards committee (NYSE), 2002, Report (NYSE, New York).

Pearce, J.H., Zahra, S.A. (1992). Board composition from a strategic contingency perspe pective. Journal of Menegment Studies29(2),411-438. 
Peraturan Menteri Dalam Negeri Republik Indonesia Nomor 64 Tahun 2011. Tentang Pedoman Penerbitan Rekomendasi Penelitian.

Pfeffer, J. (1987). A resource dependence perspective on interorganizational relations. In M. S. Mizruchi, \& M. Schwartz (Eds.), Intercorporate relations: The structural analysis of business: 22-55. Cambridge, UK: Cambridge University Press.

Prawitt, D., Smith, J., Wood, D. (2009). Internal Audit Quality and Earnings Management. The Accounting Review, 84, 1255-1280.

Jupri Lumban Toruan (2015). Pengaruh Indenpendensi, Kompetensi, Pengalaman, dan Pendidikan Terhadap Profesionalisme Auditor.

Public Oversight Board. (1994). Strengthening the professionalism of the independent auditor. Stamford, CT: POB.

Rashid, K, Islam, S dan Anderson, R. 2008. "A Comparison of Corporate Governance an Firm Performance in Developing (Malaysia) and Developed (Australia) Financial Markets". Tesis Tidak Dipublikasikan. Program Doktor. Victoria University. Melbourne

Scarbrough, P., Rama, D., Raghunandan, K. (1998). Audit committee composition and interaction with internal auditing: Canadian evidence. Accounting Horizons, 12(1), 5162.

Sekaran, Uma. 2006. Research Methods For Business, Metodologi Penelitian untuk Bisnis. Jakarta: Salemba Empat.

Shaver, D. (2005). Characteristics of corporate boards in single-industry and conglomerate media companies. International Journal of Media Management, 7(3\&4), 112-120.

Sifile Obert (2014). Internal Audit Perceptions and Their Impact on Performance of the Internal Audit Function.

Sugiyono. 2010. Metode Penelitian Bisnis. Cetakan Ke-X. CV. Bandung: Alfabeta.

Oxford Dictionary, 1998 .Management dan Pengukuran Kinerja dalam pemerintahan.

Undang - Undang Republik Indonesia No.12 Tahun 2012 tentang Pendidikan Tinggi. 